\title{
Utilizing Social Media to Encourage Domestic Tourism in Oman
}

\author{
Ali Al-Badi ${ }^{1}$, Ali Tarhini ${ }^{1} \&$ Salima Al-Sawaei ${ }^{1}$ \\ ${ }^{1}$ Department of Information Systems, College of Economics and Political Science, Sultan Qaboos University, \\ Muscat, Sultanate of Oman \\ Correspondence: Ali Tarhini, Department of Information Systems, College of Economics and Political Science, \\ Sultan Qaboos University, Muscat, Sultanate of Oman. Tel: +974 50121922. E-mail: alitarhini@squ.edu.om
}

Received: February 21, 2017

Accepted: March 17, 2017 Online Published: March 26, 2017

doi:10.5539/ijbm.v12n4p84

URL: https://doi.org/10.5539/ijbm.v12n4p84

\begin{abstract}
Nowadays people use social media in order to create, share or exchange information, pictures or videos in virtual communities and networks. Furthermore, followers can 'like', 'share' and 'comment' on other people's content or posts. Obviously, social media sites have an influence on the decision-making process, especially in the tourism sector, which has economic benefits for the country; people utilize social media channels in tourism promotional activities in order to encourage and promote domestic tourism. Hence, this Study aims to investigate how to use social media technology in order to encourage and improve domestic tourism in Oman. Data were collected using a self-administrated questionnaire from individuals who are currently using social media sites and have an interest in domestic tourism in Oman. There are three main findings: 1) there are a large number of people who use social media technology to obtain information about different attractive places they wish to visit in Oman, 2) the majority of the respondents claim that negative experiences posted on social media about a particular destination influence their travel decisions, and 3) many of the respondents indicate that the Ministry of Tourism in Oman should utilize more social media tools such as Instagram, Twitter, etc. in order to encourage domestic tourism. This research has implications not only to the Ministry of Tourism to promote domestic tourism in Oman, but also to Omani people and tourists from other countries who visit or like to visit Oman.
\end{abstract}

Keywords: social media, social network, tourism, encouraging tourism, domestic tourism, Oman, Arab world

\section{Introduction}

Nowadays millions of people around the world rely on social media for working, socializing, learning and entertainment (Al-Badi et al., 2013; Alenezi et al., 2015). Moreover, social media is a major marketing tool for products and services due to its effectiveness and low cost (Al-Wahaibi et al., 2015; Nusair et al., 2012). Therefore, several countries across the world are using social media to manage and promote their tourist destinations and services (Al-Zedjali et al., 2014). Thus, in this sector, the tourist or visitor will be highly interested and involved in the decision-making process, which will result in much searching for information from a variety of different sources (Treer, 2010; Alalwan et al., 2016). Therefore, social media can provide richer information about tourism in order to help tourists in making an informed decision.

In Oman, "the growth of the tourism sector can be verified by the increase in the number of new airports, world-class hotels, resorts and infrastructural projects in aviation, roads, rail and the maritime sectors" (ITHS, 2014). Therefore, the Ministry of Tourism in Oman is trying to encourage tourism by using e-marketing, which is using the Ministry's portal as well as online travel agents and campaigns hosted by their trade partners (Ministry of Tourism, 2013a). In addition, people in Oman are contributing to its promotion inside Oman by, for example, posting videos and photos about their towns or places they have visited in Oman using Facebook or Instagram. It is worth mentioning that the number of active users of social media tools in the Sultanate of Oman has grown from 14,000 in 2012 to 38,000 in 2013 (Al-Badi et al., 2013). Thus, it is important to study how social media can help the tourism sector in Oman, this being the purpose of our research.

The aims of this research work are: 1) to explore the extent to which social media technology is used to encourage domestic tourism in Oman; 2) to investigate how social media can be used to encourage domestic tourism in Oman (i.e. which mechanisms to use); and 3) to put forward a set of recommendations on the best way to use social media for the encouragement of domestic tourism in Oman, while avoiding any negative impacts that could be incurred in using it. 
The paper is structured as follows: After the introduction, the second section provides a literature review on social media technology in general, as well as the importance of domestic tourism, and then the impact that social media has on the tourism sector. The third section describes the research methodology and design which is used in our research. The fourth section provides research findings and discussion. Finally, a conclusion section is provided, including a summary of the study and suggestions for further research.

\section{Literature Review}

\subsection{Social Media Definition}

Social media tools are changing the way people communicate (Obeidat et al., 2016). Social media sites support the concept of creating personal relationships as well as business contacts in order to break boundaries and allow the messages to dissipate rapidly around the globe. Most social media services encourage discussion, feedback, voting, comments, and the sharing of information by all interested parties. Twitter, Facebook, Wiki, Instagram, LinkedIn, Blogs and YouTube are examples of what is termed "social media". Advances in mobile technology have made social media more accessible, allowing to become a part of people's daily lives and routines (Mangold and Faulds, 2009; Al-Ghafri \& Al-Badi, 2016; Alenezi et al., 2017).

However, social media is a very broad term and no universal definition among the scholars and researchers exist (Kaplan and Haenlein, 2010; Sharma et al., 2017, Yadav et al., 2017). A common accepted definition seems to be difficult particularly due to the existence of other concepts that came along with social media such as Web 2.0 or User Generated Content (UGC). Being closely related but not exactly the same, a distinction between all these new concepts and terms often seems to be difficult, to the extent of being used interchangeably (Morgado, 2011; Al-Badi \& Al-Qayoudhi, 2014, Nusair et al, 2013). However, Kaplan and Haenlein (2010) argue that understanding the concepts of Web 2.0 and UGC is the key to understand social media. These authors consider social media as a set on Internet-based applications that utilize Web 2.0 as its ideological and technological platform for evolution and that which enable users to create and exchange User-Generated Content. Furthermore, Jones (2009) defines it as "a category of online media where people are talking, participating, sharing, networking, and bookmarking online" (Jones, 2009). Similarly, Ranjha (2010) said that "Users of social media are connecting to each other regardless of national boundaries, culture or religion within fields and across industries" (Ranjha, 2010).

In a general sense, social media is now the normal way for the new generation of consumers to search and share information while review and experience with others (Tussyadiah and Zach, 2013). According to Lange-Faria and Elliot (2012), social media refers to Internet applications that allow their users to create, share and consume User-Generated Content. In addition, it gives people the ability to communicate and share their interests and personal information with others from all around the world (Al-Harrasi \& Al-Badi, 2014; Al-Mukhaini et al., 2014).

\subsection{Social Media Classification}

Since the advent of social media, many researchers have tried to identify and classify its different types (Fotis et al., 2011; Kaplan and Haenlein, 2010; Fischer and Reuber, 2011; Constantinides, 2009; Al-Badi, 2014), indicating an academic disagreement over social media taxonomy. Among these attempts, Kaplan and Haenlein (2010) typology has received special recognition among the researchers in the field of social media. The systematic classification of their research is based on a set of their research is based on a set of social media related theoretical frameworks including media research (social presence and media-richness) and social processes (self-presentation and self-disclosure). The authors argue that these theories build the foundation of social media. By combining the dimensions of social media and social processes, Kaplan and Haenlein (2010) propose a $3 \times 2$ scheme that classifies social media according to their level of self-presentation/self-disclosure (low and high) and their level of social presence/media richness (low, medium, high). Thus, the categories include six types of social media including blogs, social networking sites (such as Facebook), virtual social world (such as second Life), collaborative projects (such as Wikipedia), content communities (such as YouTube) and virtual game networks (such as World of Warcraft). Still, this systematic taxonomy neglects some types of social media such as microbloggings (such as Twitter).

\subsection{The Importance of the Tourism Sector for Countries}

The tourism in general is an activity that is essential to the life of nations because of its direct effects on the social, cultural, educational and economic sectors of national societies and their international relations (Higgins-Desbiolles, 2006; Abbasi et al., 2015). People may travel for their annual vacation or for many other reasons such as: adventure, healthcare treatment, fun, culture, and to enjoy new experiences (Barreda et al., 2013, 
Nusair, 2008). Economically, the tourism sector is of growing importance to many countries. "Tourism is experiencing continued growth and deepening and ,diversification is one of the fastest growing economic sectors in the world. losely linked to development and encompasses a Modern tourism is c growing number of new destinations. These dynamics have turned tourism into a key driver for socio- "economic progress(UNWTO, 2014). There are many other benefits of tourism: it create income for the country and generates new jobs. For this reason, many countries, among which is Oman, are trying to develop and motivate the tourism sector.

\subsection{The Tourism Sector in Oman}

According to (NCSI, 2014) Oman ranked the fifth best tourist destination among Arab countries in 2014. In 2014 the total tourism production in Oman totaled R.O 1.22 billion, of which R.O 205.9 million, or $20.5 \%$ was from inbound tourism, with the remaining R.O 971.1 million or $79.5 \%$ derived from domestic tourism. Inbound tourism has doubled in just under a decade in the period between 2005 and 2014; however, in the same period domestic tourism has more than tripled. The total value added to GDP from tourism in 2014 was R.O 724.5 million, or $2.2 \%$, however, the country has an ambitious plan to reach a target number of 7 million tourists in 2040, which expected to constitute 6\% of the GDP (NCSI, 2014).

\subsection{The Definition of 'Domestic Tourism' and Its Benefits for Oman}

During the past decade, tourism researchers have begun to discover the phenomenon of domestic tourism (Skanavis and Sakellari, 2011). Domestic tourism, or inbound tourism, is a type of tourism involving residents of one state travelling only within that state. In fact, domestic tourism is the first form of tourism experienced in all countries. "Domestic tourism presents a spectacular growth, especially in developing countries, but there are relatively few studies that analyse the demand for it" (Skanavis \& Sakellari, 2011). Like other countries, the Ministry of Tourism in Oman is trying to encourage domestic tourism in order to increase the revenue it brings, and thus the annual budget, helping to enhance the standard of living for local citizens and to offer opportunities for the improvement of rural regions and towns in Oman. In addition to the benefits previously mentioned, domestic tourism brings cultural and social benefits for the local citizens through the exchange of ideas and customs. For example, people from the north of Oman visit Salalah, in the south, to learn more about their customs. The interchange also brings more awareness of the achievements of national companies and institutions and provides opportunities for the developing towns through the use of domestic resources that are naturally suited to the local market as opposed to the international markets. Currently, $79.5 \%$ of total tourism expenditure comes from domestic tourism at R.O 971.1 million, compared to R.O. 250.9 million, or $20.5 \%$ from inbound tourism expenditure. The entire sector generated a value of R.O. 1.22 billion in 2014, which was and $8 \%$ increase over R.O 1.1 billion in 2013 and a 8.1\% rise over R.O 1.05 billion in 2012 (NCSI, 2014). In terms of domestic tourism expenditure by services, it is noticed that the shopping accounted for $29.5 \%$ of the total, followed by air transport services (12.1\%), accommodation services (11.6\%) and road transport services (10.8\%) (NCSI, 2014).

\subsection{Social Media in the Tourism Sector}

It is clear from the literature that the study of social media in tourism context is a growing area of interest among researchers, due to the tremendous influence of such technology on travel industry (Fotis et al., 2011). In this fields of research, most of the literature focus on main two major topics: The use of social media in the tourism industry and the influence or impact of such technology on such sector. These two perspectives are:

\subsubsection{Use of Social Media in the Tourism Sector}

Nowadays, social media tools are used in different ways by both, the tourists and the tourism agencies and organizations.

1) Usage of social media by the tourists (demand side): Amaro et al. (2016) has stated that typically, travelers' use of social media is divided in three phases, before, during and after the trip. The types of usage are:

- Pre-trip: Social media plays an important role before travelling, by providing ideas, reducing risk and making it easier to imagine what places will be like. Cox et al. (2009) have found that social media are predominantly used before travelling. During this phase, travelers search for ideas on where to go, information on accommodations options, excursions and other leisure activities. During this phase, it has been shown that a higher percentage of travelers turn to user generated content (UGC), when visiting a destination for the first time, as well as visiting an international destination (Simms, 2012). Before the trip, travelers are essentially consuming social media (they are reading and viewing UGC) but are not actively participating by creating content. (Manap \& Adzharudin, 2013) has presented UGC as the opposite to traditional forms of media and marketing since 
content is generated by the consumer rather than the marketer.

- During the trip: During the trip, travelers' use of social media for travel purposes has been found much lower than before the trip (Cox et al., 2009). During this phase, travelers not only consume social media to find holiday related information, but also begin to share their travel experiences, by producing comment and review on UGC, however producing social media content is much lower than consuming (Fotis et al., 2011).

- Post-trip: After the trip, travelers use social media to post information regarding their trip thought, comments, reviews, photos or pictures. It is during this phase that social media and UGC producing takes place (Fotis et al., 2011).

2) Usage of social media by the tourism agencies (supply side): The existing literature has primarily been dedicated to two main patterns of social media utilization in the tourism industry: social media as an instrument for destination or tourism promotion (Hays et al., 2013; Munar, 2012; Stankov et al., 2010) and social media's role in travellers' decision making via data analytics out of the crowd sourced data collected by the users (Parra-López et al., 2011; Chung and Koo, 2015). These two main patterns are:

- As a marketing and promotion tools: The dynamics of marketing and promotions are changing, moving from passive advertisements on television to the new horizons of online social media (Ranjha, 2010). Given the prevalence of social media use among tourists, social media become indispensable platforms for tourism marketers (Huang, 2012; Dioko et al., 2011; Almajali et al., 2016). Within tourism marketing, several studies have looked at the use of social media as communication tools for promoting products or services, creating interactive conversations and building customers relationships. This is called Social Media Marketing or S-Marketing (Ranjha, 2010; Orozco et al., 2015). Social media marketing programs usually center on efforts to create content that attracts attention and encourages readers to share it with their social networks (Hassouna et al., 2015). A promotional message spreads from user to user and presumably resonates because it appears to come from a trusted third-party source, as opposed to the brand of company itself. Hence, this form of marketing is driven by word-of-mouth, meaning it results in earned media rather than paid media. Research has shown that using social media as marketing tool by tourism organizations is still in the introductory phase (Ranjha, 2010; Al-Harrasi, \& Al-Badi, 2013).

- As a tourism management tool: Several researchers have focused on how social media can be used as a tourism management tool by collecting and analyzing user generated content (UGC). For example (Floris and Campagna, 2014; Hamoud et al., 2016) has shown that the use of social media can also offer new opportunities for decision-support in tourism planning. With analyzing the data from social media sources, the tourism agencies can improve understanding of the motivations of tourists and tailoring tourism service supply, decision making can be facilitated by emphasizing the strengths of tourist destinations for past and potentials visitors.

\subsubsection{The Influence or the Impact of Social Media in the Tourism Sector}

How social media is important for the tourism sector continues to be an important question. From this perspective, literature review focuses on the impact of social media on travelers' travel planning process and decisions. Several research papers have shown how social media influence positively the tourism sector, but in (Minazzi, 2015), the author represents a valuable scientific work where an in-depth study of the impacts social media exert on tourism demand and supply sides.

Social media is one source of information that influences people's decision about the journey they plan to make. Online social travel networking is also changing the way tourists plan their trips (Maqableh et al., 2015). Miguéns et al. (2008) stated that these websites and applications allow users to interact and provide reviews on hotels or on local tourist attractions (Miguéns et al., 2008). People use social media to collect information about the best trips and the most attractive places to visit in their travel destination. For example, a family that is preparing to visit Nizwa city in Oman can search for information about it on social media sites and ask communicate with people from Nizwa to guide them, also tourist may use people rating, comments and opinions of other tourists on social media about different services and destinations in and around Nizwa. Usually people trust in others' comments and responses but, despite the great benefits and importance of social media sites, they have their challenges as well, and reliability and credibility are arguably among the greatest of these at this time. Moreover, potential tourists prefer to collect information from several different social media sites according to their needs. This information includes: weather, prices, hotel information, transportation, restaurants and so on.

Being aware of the key importance of the role of modern information and communication technologies and in particular social media, in order to facilitate access to information and services, and to promote interaction between concerned parties, and to promote tourism in Oman, the Ministry of Tourism in Oman has launched its 
Electronic Tourism Portal in 2010 (Ministry of Tourism, 2013b).

\section{Research Methodology}

In this exploratory research a questionnaire was used to investigate how social media could be used to encourage domestic tourism in Oman. In a questionnaire large amounts of data can be collected from a large number of people in a short period of time and in a relatively cost-effective way. The analysis, outcomes, general conclusions, recommended policy and identified areas for future research all depend on how well the questionnaire is constructed. Therefore, focusing on its construction is considered the most important part of the research. The questionnaire was divided into four parts:

1) The collection of general information such as, age, gender, educational level... etc.

2) An investigation of the extent to which social media is used to encourage tourism locally in Oman, and the possible negative effects of using social media for the purpose of encouraging tourism.

3) An investigation into how social media can be used to encourage domestic tourism in Oman.

4) Additional comments and feedback.

The questionnaire was distributed amongst individuals from high schools and universities who are using social media websites and have an interest in travelling locally in Oman. It was distributed in two ways: Firstly, by publishing a link to the online questionnaire on Twitter, requesting replies from those interested in travelling locally in Oman, and secondly, the questionnaire was printed and distributed between individuals who were using the social media sites and had an interest in travelling locally in Oman. The questionnaire was distributed from 15th to 25th April, 2015. The number of respondents during this time was 176 individuals.

\section{Findings and Discussion}

After collecting the data through the questionnaire, it was analyzed to find out the extent to which social media is used by people wishing to travel locally in Oman and, indeed, which social media might be used to encourage domestic tourism in Oman (what mechanisms to use).

\subsection{Description of the Sample}

The sample of respondent has been selected randomly from several universities and schools in Oman. As indicated in the Table 1, most of the respondents are female and are between 21-25 years old. In terms of profession and education level, the majority of respondents are students with Bachelor degree.

Table 1. Respondents demographic data (Bio Data)

\begin{tabular}{lclc}
\hline Gender & $\%$ & Education Level & $\%$ \\
\hline Male & 28 & PhD & 0.5 \\
Female & 72 & Masters & 7 \\
Age & & Bachelor & 63.6 \\
$15-20$ & 10.7 & Diploma & 22.7 \\
$21-25$ & 71.5 & High School & 6.5 \\
$26-30$ & 7.9 & Profession & 80.1 \\
$31-35$ & 4.5 & Student & 14.7 \\
$36-40$ & 3.4 & Employed & 0 \\
$40<$ & 1.7 & Self-employed & 5.2 \\
\hline
\end{tabular}

\subsection{Travel History and Experience}

The travel history and experience of the respondents is summarized in Table 2. As indicated in that table, the majority of the respondents have experience in travelling internationally, most of them with families for vacation. Mostly, the respondents travel one or twice a year and these travel trips are planned mostly by themselves. 
Table 2. Respondents Travel Data (travelling information)

\begin{tabular}{lclc}
\hline Have travelled internationally: & $\%$ & Travel Purpose: & $\%$ \\
\hline Yes & 67.6 & Family vacation & 71.5 \\
No & 32.4 & Adventures & 3.4 \\
Frequency of holiday travel & & Business & \\
inside Oman: & & & 84.6 \\
Once a year & 34.6 & Planning trip: & 15.4 \\
Once in 6 months & 34 & Themselves & \\
Once in 3 month & 15.9 & Via a travel agent & \\
Every month & 9 & & \\
Every week & 6.1 & & \\
\hline
\end{tabular}

\subsection{Usage of Social Media for Planning Domestic Tourism in Oman}

The second part of the survey contains questions about the usage of social media sites and applications for planning domestic travel in Oman, in order to gauge the extent to which social media is used for planning travel locally. It was found that $48 \%$ of the respondents used social media sites to collect information, $62 \%$ were using it for the purpose of entertainment, 54\% used it for work or study, and 37\% used it for the purpose of socializing. Moreover, it has been shown that there are a big number of people who use social media sites to get information and photos about places they intent to visit locally in Oman; this proves that most people in Oman are using social media for the purpose of domestic tourism, and they have the willingness to encourage domestic tourism in Oman.

In addition, more than the half of the respondents said that they sometimes uploaded photos and shared them with others through social media upon returning from a trip, whereas $28 \%$ did this every time, while $16 \%$ of them never used social media to upload photos. Most people preferred to use WhatsApp and Instagram to share photos with others. Uploading and sharing photos of places in Oman through social media has the potential of becoming the most powerful way to encourage domestic tourism in Oman. However, in answer to the question "Do the negative or bad experiences about a travel destination that are posted on social media sites influence your travel decisions?" $54.5 \%$ said they could well be influenced in their travel decisions by these negative postings, $15.9 \%$ said that they were definitely influenced, whereas $13 \%$ said they were not, and $15.9 \%$ said they did not know. Thus it would appear that most people are interested in information and photos posted on social media sites, and are also influenced in their travel decisions by negative or bad experiences about a travel destination that are posted on social media sites. It is obvious from the results that word of mouth has a critical role to play in decision-making in tourism.

When asked about sources of information they use to plan their domestic holiday, the majority of respondents (67\%) replied that their source is friends' suggestions. $40.3 \%$ said they already knew the places, $20 \%$ said that they sourced information through social media, and 18\% said that their source is promotion through the internet.

When asked about the role of the Ministry of Tourism in promoting domestic tourism in Oman through social media sites, the majority of respondents $(47 \%)$ replied that they did not know about the tourism promotion on social media. 20.4\% agree that the Ministry of Tourism website and its accounts on other social media sites are promoting domestic tourism in Oman, $10.2 \%$ strongly agree, $3.9 \%$ strongly disagree with that, and $18.8 \%$ disagree. Actually, the main Ministry of Tourism website contains extensive information about domestic destinations in Oman, about hotels, shops, caves, weather, maps and locations along with photos. The results of the questionnaire, however, reveal that most people do not know about the Ministry of Tourism website.

When asked about their reasons for using social media to collect and search for information, $71 \%$ of respondents replied that it was because it is easy to get information through social media sites, $34 \%$ mentioned receiving insights from the comments made by people with similar interests, $2.8 \%$ said it was because of the higher level of trust they had in the opinions and observations found on social media, and only $5 \%$ considered it to be a reliable source. It is obvious from the results that few people trust the information they obtained from social media sites. However, have they been satisfied with the information gathered through social media? Did it help them in making their decision? $72 \%$ said that they were satisfied with the information gathered through social media and that it helped them to make decisions, and $12.5 \%$ said they are not satisfied with the information gathered through social media. 


\subsection{How Social Media Could Be Used to Encourage Domestic Tourism in Oman}

The third part of the survey contains questions about how the social media could be used to encourage domestic tourism in Oman. Surely, the Ministry of Tourism should be playing a critical role in the promotion of domestic tourism. Therefore, there is a question asked about the types of social media that the Ministry of Tourism should be using to encourage domestic tourism. 66\% of respondents choose Twitter, 39\% chose Facebook, $77.8 \%$ chose Instagram, 53\% chose YouTube, $19 \%$ choose LinkedIn and other types of social medial such as, WhatsApp, and Snap Chat. Most respondents preferred Twitter and Instagram, thus indicating that the Ministry of Tourism should utilize these mediums to encourage domestic tourism.

$90 \%$ of the respondents declared it to be very important for travel/tourism companies/agents in Oman to promote domestic tourism through social media, while only $10 \%$ said that there was no need for this.

Finally, at the end of the questionnaire there is a space for any comments regarding using social media to encourage domestic tourism in Oman. The following are some of the comments made by respondents:

Local people in Oman should utilize social media in domestic tourism promotion.

- The Ministry of Tourism should find out who the main influencers are in social media in the Gulf currently, follow them and see what they can do to promote domestic tourism in Oman. For example, invite them to visit Oman and take them on a trip, then they will take some photos and videos and post them on their snap chat account and Instagram.

- There should be official accounts on social media sites to promote domestic tourism in our country; these accounts should be managed by the Ministry of Tourism.

- Create new applications on mobile phones that will guide the tourists.

In summary, we can conclude from our study that most of the respondents rely to social media technology to plan their domestic destination trips.

\section{Conclusion}

The purpose of this research work was to gauge the extent to which the technology of social media is used to encourage domestic tourism in Oman. One of the more significant findings is that more than half of respondents are using social media to obtain information about places they intend to visit in Oman. When asked about sources of information they used to plan their domestic holiday, the majority of respondents replied that their main source is friends' suggestions; while others stated that they either already knew the places or looked on social media. Friends' suggestions may be accessed through social media sites.

In addition, this study aims to investigate how social media can be used to encourage domestic tourism in Oman (i.e. which mechanisms to use); it is obvious from the findings that the Ministry of Tourism in Oman should utilize Instagram and Twitter or any other social media technology to encourage domestic tourism.

However, the findings of the study have highlighted a number of barriers and limitations in using social media in general for people in Oman, such as privacy concerns and cultural factors. It is clear that the culture has a significant impact on how much social media is used. After all, social media is considered as a cultural-change factor. Therefore, doing more research in this field will enrich the whole study. To be fair, data from only a few people is not projectable. That is, the sample size is too small to be valid across the general population. Further research is still needed to better understand how to promote the active participation of social media in tourism in general

\section{References}

Abbasi, M. S., Tarhini, A., Elyas, T., \& Shah, F. (2015). Impact of individualism and collectivism over the individual's technology acceptance behaviour: A multi-group analysis between Pakistan and Turkey. $\begin{array}{llll}\text { Journal of Enterprise Information } & \text { Management, 28(6), }\end{array}$ https://doi.org/10.1108/JEIM-12-2014-0124

Alalwan, A. A., Rana, N. P., Algharabat, R., \& Tarhini, A. (2016, September). A Systematic Review of Extant Literature in Social Media in the Marketing Perspective. In Conference on e-Business, e-Services and e-Society (pp. 79-89). Springer International Publishing. https://doi.org/10.1007/978-3-319-45234-0_8

Al-Badi, A. H., Okam, M. O., Al Roobaea, R., \& Mayhew, P. J. (2013). Improving usability of social networking systems: a case study of LinkedIn. Journal of Internet Social Networking \& Virtual Communities, 17-23.

Al-Badi, A. H., AlHinai, Y. S., Sharma, S. K., \& Williams, S. (2013). Usage of social networking tools in research and collaboration. Journal of Emerging Trends in Economics and Management Sciences, 4(6), 
515-523.

Al-Badi, A. H., \& Al-Qayoudhi, W. S. (2014). Adoption of Social Networks In Business: Study Of Users And Potential Users In Oman. The International Business \& Economics Research Journal (Online), 13(2), 401-417. https://doi.org/10.19030/iber.v13i2.8457

Al-Badi, A. H., (2014). The adoption of social media in government agencies: Gulf Cooperation Council case study. Journal of Technology Research, 5(1), 1-26.

Alenezi, H., Tarhini, A., \& Sharma, S. K. (2015). Development of quantitative model to investigate the strategic relationship between information quality and e-government benefits. Transforming Government: People, Process and Policy, 9(3), 324-351. https://doi.org/10.1108/TG-01-2015-0004

Alenezi, H., Tarhini, A. Masa'deh, R. Alalwan, AA. \& Al-Qirim, N. (2017). Factors affecting e-government adoption in Kuwait: A qualitative study. The Electronic Journal of e-Government. 15(2), 84-102.

Al-Dmour, H., Al-Madani, S., Alansari, I., Tarhini, A., \& Al-Dmour, R. H. (2016). Factors Affecting the Effectiveness of Cause-Related Marketing Campaign: Moderating Effect of Sponsor-Cause Congruence. International Journal of Marketing Studies, 8(5), 114.

Al-Harrasi, A. S., \& Al-Badi, A. H. (2014). The impact of social networking: A study of the influence of smartphones on college students. Contemporary Issues in Education Research (Online), 7(2), 129-136. https://doi.org/10.19030/cier.v7i2.8483

Al-Harrasi, A. S., \& Al-Badi, A. H. (2013). The Impact of Social Networking: A Case Study of the Influence of Smartphones on College Students. The Clute Institute International Academic Conference, 689-694.

Al-Ghafri, R. K., \& Al-Badi, A. H. (2016). Users' Activities on Social Media as indicators of Self-Esteem: a Case Study in Oman. Journal of Internet Social Networking \& Virtual Communities, (1), 1-12.

Almajali, D. A., Masa'deh, R. E., \& Tarhini, A. (2016). Antecedents of ERP systems implementation success: a study on Jordanian healthcare sector. Journal of Enterprise Information Management, 29(4), 549-565. https://doi.org/10.19030/cier.v7i2.8483

Al-Mukhaini, E. M., Al-Qayoudhi, W. S., \& Al-Badi, A. H. (2014). Adoption of social networking in education: A study of the use of social networks by higher education students in Oman. Journal of International Education Research, 10(2), 143-154. https://doi.org/10.19030/jier.v10i2.8516

Al-Wahaibi, H. A., Al-Mukhaini, E. M., Al-Badi, A. H., \& Ali, S. (2015, February). A case study of the employment of social media in government agencies in Oman. In GCC Conference and Exhibition (GCCCE), 2015 IEEE 8th (pp. 1-6). IEEE. https://doi.org/10.1109/ieeegcc.2015.7060089

Al-Zedjali, K. H., Al-Harrasi, A. S., \& Al-Badi, A. H. (2014). Motivations for Using Social Networking Sites by College Students for Educational Purposes. World Academy of Science, Engineering and Technology, International Journal of Social, Behavioral, Educational, Economic, Business and Industrial Engineering, $8(8), 2577-2580$.

Amaro, S., Duarte, P., \& Henriques, C. (2016). Travelers' use of social media: A clustering approach. Annals of Tourism Research, 59(1), 1-15. https://doi.org/10.1016/j.annals.2016.03.007

Barreda, A., Nusair, K., Okumus, F., \& Bilgihan, A. (2013). Developing a brand structure pyramid model for travel-related online social networks. Tourism Review, 68(4), 49-70. https://doi.org/10.1108/TR-09-2013-0055

Barreda, A., Okumus, F., Nusair, K. K., \& Bilgihan, A. (2016). The Mediating Effect of Virtual Interactivity in Travel-Related Online Social Network Websites. International Journal of Hospitality \& Tourism Administration, 17(2), 147-178. https://doi.org/10.1080/15256480.2015.1130669

Bilgihan, A., Barreda, A., Okumus, F., \& Nusair, K. (2016). Consumer perception of knowledge-sharing in travel-related Online Social Networks. Tourism Management, 52, 287-296. https://doi.org/10.1016/j.tourman.2015.07.002

Chung, N., \& Koo, C. (2015). The use of social media in travel information search. Telematics and Informatics, 32(2), 215-229. https://doi.org/10.1016/j.tele.2014.08.005

Constantinides, E. (2009, January). Social Media/Web 2.0 as marketing parameter: An introduction. In Proceedings of 8th international congress marketing trends (pp. 15-17).

Cox, C., Burgess, S., Sellitto, C., \& Buultjens, J. (2009). The role of user-generated content in tourists' travel 
planning behavior. Journal of Hospitality Marketing \& Management, 18(8), 743-764. https://doi.org/10.1080/19368620903235753

Dioko, L., Harrill, R. \& Munar, A. (2011). Tourist-created content: rethinking destination branding. International Journal of Culture, Tourism and Hospitality Research, 5(3), 291-305. https://doi.org/10.1108/17506181111156989

Fischer, E., \& Reuber, A. R. (2011). Social interaction via new social media:(How) can interactions on Twitter affect effectual thinking and behavior?. Journal of business venturing, 26(1), 1-18. https://doi.org/10.1016/j.jbusvent.2010.09.002

Floris, R. \& Campagna, M., (2014), Social Media Data in Tourism Planning: Analysing Tourists' Satisfaction in Space and Time, In the proceeding of Real Corp 2014 997-1003. Vienna, Austria, 21-23 May 2014.

Fotis, J., Buhalis, D. \& Rossides, N., (2011). Social media impact on holiday travel planning: The case of Russian and the FSU markets. International Journal of Online Marketing (IJOM), 1(4), 1-19. https://doi.org/10.4018/ijom.2011100101

Hamoud, M. W., Tarhini, A., Akour, M. A., \& Al-Salti, Z. (2016). Developing the main knowledge management process via social media in the IT organisations: A conceptual perspective. International Journal of Business Administration, 7(5), 49-64.

Hassouna, M., Tarhini, A., Elyas, T., \& AbouTrab, M. S. (2015). Customer Churn in Mobile Markets: A Comparison of Techniques. International Business Research, 8(6), 224-237. https://doi.org/10.5539/ibr.v8n6p224

Hays, S., Page, S. J. \& Buhalis, D., (2013). Social media as a destination marketing tool: its use by national tourism organisations. Current issues in Tourism, 16(3), 211-239.

Higgins-Desbiolles, F. (2006). More than an "industry": The forgotten power of tourism as a social force. Tourism Management, 27(6), 1192-1208. https://doi.org/10.1016/j.tourman.2005.05.020

Huang, L., (2012). Social media as a new play in a marketing channel strategy: Evidence from Taiwan travel agencies' blogs. Asia Pacific Journal of Tourism Research, 17(6), 615-634.

ITHS, (2014). Capitalizing on investment opportunities in Oman's tourism sector. Retrieved from http://www.iths-oman.com/2014/ iths-capitalizing-on-investment-opportunities-in-omans-tourism-sector/

Jones, R. (2009). Social Media Marketing 101, Part 1. Retrieved from http://searchenginewatch.com/sew/opinion/2064413/social-media-marketing-101-part

Kaplan, A. M., \& Haenlein, M., (2010). Users of the world, unite! The challenges and opportunities of Social Media. Business horizons, 53(1), 59-68. https://doi.org/10.1016/j.bushor.2009.09.003

Lange-Faria, W., \& Elliot, S., (2012). Understanding the role of social media in destination marketing. Tourismos: An International Multidisciplinary Journal of Tourism, 7(1), 193-211.

Manap, K. A. \& Adzharudin, N. A., (2013). The Role of User Generated Content (UGC) in Social Media for Tourism Sector. In the proceeding of The 2013 WEI International Academic Conference Proceedings, Berlin, Germany (pp. 52-58).

Mangold, W. G. \& Faulds, D. J., (2009). Social media: The new hybrid element of the promotion mix. Business horizons, 52(4), 357-365. https://doi.org/10.1016/j.bushor.2009.03.002

Maqableh, M., Rajab, L., Quteshat, W., Masa'deh, R., Khatib, T., \& Karajeh, H. (2015). The Impact of Social Media Networks Websites Usage on Students' Academic Performance, Communications and Network, 7, 159-171. https://doi.org/10.4236/cn.2015.74015

Miguéns, J., Baggio, R., \& Costa, C. (2008). Social media and tourism destinations: TripAdvisor case study. Advances in tourism research, 26(28), 1-6.

Minazzi, R. (2015). Social media marketing in tourism and hospitality. Springer, NY: USA. https://doi.org/10.1007/978-3-319-05182-6

Ministry of Tourism, (2013a). Marketing. Retrieved from http://goo.gl/PGLXac

Ministry of Tourism, (2013b). Welcome to Oman Tourism Portal. Accessed on 7/1/2017. Retrieved from http://goo.gl/4fUvSa

Morgado, L., (2011). The networked class in a master's program: Personalization and Openness through Social 
Media. Educating Educators with Social Media, 1(2), 135-150.

Munar, A. M. (2012). Social media strategies and destination management. Scandinavian Journal of Hospitality and Tourism, 12(2), 101-120. https://doi.org/10.1080/15022250.2012.679047

NCSI. (2014). The reality of the Omani tourism. Information and statistics, National Centre for Statistics and Information, Oman.

Nusair, K., \& Kandampully, J. (2008). The antecedents of customer satisfaction with online travel services: A conceptual model. European Business Review, 20(1), 4-19. https://doi.org/10.1108/09555340810843663

Nusair, K., Erdem, M., Okumus, F., \& Biligan, A. (2012). Users attitudes toward online social networks in travel. Social media in travel, tourism and hospitality: Theory, practice and cases. Farnham: Ashgate Publication.

Nusair, K. K., Bilgihan, A., \& Okumus, F. (2013). The role of online social network travel websites in creating social interaction for Gen Y travelers. International journal of tourism research, 15(5), 458-472. https://doi.org/10.1002/jtr.1889

Obeidat, B. Y., Al-Suradi, M., Masa'deh, R. \& Tarhini, A. (2016). The impact of knowledge management on innovation: An empirical study on Jordanian consultancy firms. Management Research Review, 39(10), 1214-1238. https://doi.org/10.1108/MRR-09-2015-0214

Orozco, J., Tarhini, A., \& Tarhini, T. (2015). A framework of IS/business alignment management practices to improve the design of IT Governance architectures. International Journal of Business and Management, 10(4), 1-12. https://doi.org/10.5539/ijbm.v10n4p1

Parra-López, E., Bulchand-Gidumal, J., Gutiérrez-Taño, D. \& Díaz-Armas, R., (2011). Intentions to use social media in organizing and taking vacation trips. Computers in Human Behavior, 27(2), 640-654. https://doi.org/10.1016/j.chb.2010.05.022

Ranjha, A. (2010). Promoting tourism in Abu Dhabi using social media, a PhD thesis at School of Computer Science and Communication, Royal Institute of Technology. KTH Computer Science and Communication, Stockholm, Sweden.

Sharma, S. K., Govindaluri, S. M., Muharrami, S. M., \& Tarhini, A. (2017). A multi-analytical model for mobile banking adoption: A developing country perspective. Review of International Business and Strategy, 27(1), $1-27$.

Simms, A., (2012), Online user-generated content for travel planning-different for different kinds of trips? e-Review of Tourism Research, 10(3), 76-85.

Skanavis, C. \& Sakellari, M., (2011). International tourism, domestic tourism and environmental change: Environmental education can find the balance. Tourismos: An International Multidisciplinary Journal of Tourism, 6(1), 233-249.

Stankov, U., Lazic, L. \& Dragicevic, V., (2010). The extent of use of basic Facebook user-generated content by the national tourism organizations in Europe. European Journal of Tourism Research, 3(2), 105-120.

Tarhini, A., El-Masri, M., Ali, M. \& Serrano, A. (2016). Extending the UTAUT model to understand the customers' acceptance and use of internet banking in Lebanon: A structural equation modeling approach. Information Technology \& People, 29(4), 830-849. https://doi.org/10.1108/ITP-02-2014-0034

Treer, E. (2010). Social media: an interesting option for tourism destination promotion?. Unpublished $\mathrm{PhD}$ thesis, Tourism Programme, Aalborg University.

Tussyadiah, I. \& Zach, F. (2013). Social media strategy and capacity for consumer co-creation among destination marketing organizations. In Information and Communication Technologies in Tourism 2013Springer, (242-253). https://doi.org/10.1007/978-3-642-36309-2_21

UNWTO, (2014). Tourism-an economic and social phenomenon. Retrieved from http://www2.unwto.org/content/why-tourism

Yadav, R., Sharma, S. K., \& Tarhini, A. (2016). A multi-analytical approach to understand and predict the mobile commerce adoption. Journal of enterprise information management, 29(2), 222-237. https://doi.org/10.1108/JEIM-04-2015-0034 


\section{Copyrights}

Copyright for this article is retained by the author(s), with first publication rights granted to the journal.

This is an open-access article distributed under the terms and conditions of the Creative Commons Attribution license (http://creativecommons.org/licenses/by/4.0/). 